\title{
INVESTIGATION OF IMPINGEMENT HEAT TRANSFER FOR AIR-SAND MIXTURE FLOW
}

\author{
Mustafa J Al-Dulaimia , Adnan A. Abdul Rasool ${ }^{b}$, F A Hamad ${ }^{c}$,
}

a. Mech. Eng. Dept, college of Engineering, Al-Mustansiriya University, Baghdad, Iraq (Former postgraduate student)

mustafa.ingenium@gmail.com

b. Mech. Eng. Dept, college of Engineering, Al-Mustansiriya University, Baghdad, Iraq.

adn1954@yahoo.com

c. School of Science \& Engineering, Teesside University, Middlesbrough, TS1 3BA, UK

\section{F.Hamad@tees.ac.uk}




\begin{abstract}
Heat transfer between a heated flat plate and normal impinging gas-solid two-phase jet flow has been investigated. A single jet from a nozzle of $10 \mathrm{~mm}$ diameter at nozzle-to-plate distance/nozzle diameter in the range of 2 to 8 was used. Natural sand particles with average diameters of 220, 350 and $550 \mu \mathrm{m}$ are used as a solid phase. The effect of particle size and loading ratio (mass of sand/ mass of air) at different jet velocities on impingement cooling characteristics of flat plate are investigated. The numerical simulations are performed with the ANSYS Fluent 14.7 for steady, three-dimensional, incompressible turbulent flow using Eulerian simulation for gas phase and Lagrangian simulation for sand particles. The experimental results show that the existence of sand particles decreases the Nusselt number compared to air jet flow. The single and two-phase flow experimental results are compared well with predictions when the particle reflection option is used in the simulation. The discrepancy in the local values near the stagnation point can be attributed to the complex nature of the two-phase flow at the stagnation point that includes reflection of sand particles at different angles.
\end{abstract}

Key words: Air-sand jet flow, impingement heat transfer, loading ratio, CFD simulation, particle reflection 


\section{Nomenclature:}

\begin{tabular}{|c|c|}
\hline$A_{s}$ & Plate surface area $\left(\mathrm{m}^{2}\right)$ \\
\hline$c_{p}$ & Specific heat $(\mathrm{J} / \mathrm{kg} \mathrm{K})$ \\
\hline$d_{p}$ & Particle diameter (mm) \\
\hline$D$ & Nozzle diameter (mm) \\
\hline$E$ & Total energy from the electric heater $(\mathrm{J})$ \\
\hline$F$ & $\begin{array}{l}\text { Additional body force added through interaction with } \\
\text { particles }(\mathrm{N})\end{array}$ \\
\hline$h$ & Local heat transfer coefficient $\left(\mathrm{W} / \mathrm{m}^{2} \mathrm{~K}\right)$ \\
\hline$h_{a v}$ & Average heat transfer coefficient $\left(\mathrm{W} / \mathrm{m}^{2} \mathrm{~K}\right)$ \\
\hline I & DC electrical Current $(A)$ \\
\hline$k_{f}$ & Thermal conductivity of air (W/m K) \\
\hline$k$ & Turbulence kinetic energy $\left(\mathrm{m}^{2} / \mathrm{s}^{2}\right)$ \\
\hline $\mathrm{Nu}$ & Local Nusselt number (hD/Kf $)$ \\
\hline$N u_{a v}$ & Average Nusselt number $\left(h_{a v} D / K_{f}\right)$ \\
\hline$P$ & Static Pressure $\left(\mathrm{N} / \mathrm{m}^{2}\right)$ \\
\hline $\operatorname{Pr}_{t}$ & Turbulent Prandtl number \\
\hline$q_{\text {total }}$ & Total input energy (W) \\
\hline$q_{\text {conv }}$ & Heat transfer by convection (W) \\
\hline$q_{\text {loss }}$ & Heat transfer by radiation (W) \\
\hline$r$ & Radial Distance from the centre of the jet $(\mathrm{mm})$ \\
\hline $\operatorname{Re}$ & Reynolds number $\left(U_{J} D / v\right)$ \\
\hline$S_{h}$ & The heat source term \\
\hline$S_{i j}$ & Strain rate tensor, $1 / \mathrm{s}$ \\
\hline$S_{m}$ & The mass source term added to the system through \\
\hline
\end{tabular}


dispersion of the second phase

$t$

$T$

$T_{x}$

$T_{s}$

$T_{\infty}$

$U_{J}$

$U_{T}$

$u$

$u_{i}^{\prime}$

$u_{i p} \quad$ Particle velocity, $\mathrm{m} / \mathrm{s}$

V

Z

$y$

$y^{+}$

$\varepsilon$

$\mu$

$\mu_{t}$

v

$\rho$

$\Gamma$

$\rho_{p}$

$x, y, z$

Time (s)

Temperature (K)

Jet Velocity $(\mathrm{m} / \mathrm{s})$

Velocity, $\mathrm{m} / \mathrm{s}$

Voltage (Volt)

Air viscosity $\left(\mathrm{N} \mathrm{s} / \mathrm{m}^{2}\right)$

Air density $\left(\mathrm{kg} / \mathrm{m}^{3}\right)$

Loading ratio
Local surface temperature $\left({ }^{\circ} \mathrm{C}\right)$

Average surface temperature on the target plate $\left({ }^{\circ} \mathrm{C}\right)$

Temperature of the impinging jet $\left({ }^{\circ} \mathrm{C}\right)$.

Friction velocity $(\mathrm{m} / \mathrm{s})$

Turbulence fluctuation, $\mathrm{m} / \mathrm{s}$

Nozzle-to-plate distance $(\mathrm{m})$

Distance from the plate surface $(\mathrm{m})$

Dimensionless distance from the plate surface

dissipation rate of kinetic energy $\left(\mathrm{m}^{2} / \mathrm{s}^{3}\right)$

turbulent viscosity $(\mathrm{kg} / \mathrm{m} \mathrm{s})$

Kinematic viscosity $\left(\mathrm{m}^{2} / \mathrm{s}\right)$

Particle density $\left(\mathrm{kg} / \mathrm{m}^{3}\right)$

Cartesian coordinates (m) 


\section{Introduction}

Jet Impingement of single phase flow used for cooling hot surfaces in industrial processes because of the very high heat transfer rate by forced convection which reviewed by Zuckerman and Lior [1]. Introducing a second phase such as solid particle can cause augmentation or attenuation of turbulence depending on particles size, particles concentration, slip velocity and the jet velocity. The interaction between the particles with the gas and surfaces affect the heat transfer. Jet impingement cooling is used in a number of industrial systems such as turbine blades, heat exchanger, cooling of steel products after rolling, etc. A summary of some recent published works in the literature is given below.

Takehiko et al [2] used multiple impinging jets to study the heat transfer by mixing glass beads and graphite particles with air jet. The heat transfer was enhanced when graphite particles are used but it was decreased when glass beads was used. The results show that a belt-shaped dense region was formed near the wall after impingement of graphite particle but the glass beads particles are scattered after impingement. Shimizu et al [3] studied the heat transfer of jet impingement of nitrogen-graphite two-phase flow. The Reynolds number and the particle load ratio were in the range of $4.7 \times 10^{4}-2 \times 10^{5}$ and $0-2.5$, respectively were used.

Yoshida et al [4] investigated the heat transfer of impinging jet of gas-solid suspension using laser-Doppler anemometry. They used two-phase flow consisting air and glass beads of diameter $48.9 \mu \mathrm{m}$ with standard deviation $8.7 \mathrm{~m} \mu$ to carry out a heat transfer experiments for loading ratio varied in range of 0 to 0.8 and Reynolds number 10000 . The Nusselt number increased to be 2.7 times the single flow which attributed to the drastic change in the turbulence intensity at the heated surface. They also noted that the static electricity charge in fine particles influence the flow and temperature fields. A humidifier was installed upstream of the nozzle to maintain 
the humidity at about $65 \%$ which gives a stable repeatable measurements. The difference between the results from [4] and [2] may explained by the difference in humidity.

Yokomine and Shimizu [5] Conducted experimental investigation to demonstrate the heat transfer performance of dense nitrogen-solid suspension impinging jet for diverter cooling of the fusion power reactor. The ranges of examined nozzle Reynolds number $(\operatorname{ReN})$ and thermal loading ratio $\Gamma_{\text {th }}$ were $5.5 \times 10^{4} \leq \operatorname{ReN}_{\mathrm{N}} \leq 2.4 \times 10^{5}$ and $0 \leq \Gamma_{\text {th }} \leq 8.55$ respectively. Spherical glassy-carbon (G-C) particles with $26 \mu \mathrm{m}$ in diameter and fine graphite particles with $10 \mu \mathrm{m}$ in diameter were used in the experiments. It was observed that changing the particles from hard glassy carbon to fine graphite particles is effective not only for anti-erosion but also for heat transfer enhancement in by increasing heat capacity. Turbulence augmentation by particles is also important for heat transfer enhancement in addition to the increased in heat capacity. However, increasing the solid loading is likely to lead to the saturation of heat transfer enhancement effect, on the contrary, to the attenuation of turbulence. Shimizu et al [6] studied the nitrogen-carbon impinging jet from a single nozzle under high heat flux and high temperature. They found that the heat transfer coefficient was $15 \mathrm{~kW} / \mathrm{m}^{2} \mathrm{~K}$ at solid loading ratio 4.5 .

Jin-song et al [7] investigated the influence of particles on impingement heat transfer from tube in gas-solid two-phase flow. The solid particles used in their work were ash with mean diameter of 65 micron and sand with mean particle diameters of 120 and $320 \mu \mathrm{m}$. Solid loading ratio in the range of $0-2.5$ and solid particle diameters of 63 , 150, $385 \mu \mathrm{m}$ were used. Heat transfer was evidently enhanced with increasing solid loading ratio, but the solid particles reduced instead of enhanced the heat transfer at solid loading ratio ( $\Gamma<0.015 \mathrm{~kg}$ of sand $/ \mathrm{kg}$ of air). This negative effect was mainly due to turbulence suppression by particles. It was found that the Nusselt number for a Reynolds number of 12000 and a solid loading ratio of $1.0 \mathrm{~kg} / \mathrm{kg}$ increases with reducing particle size. The smaller the particles are, the larger the number of particles in a unit volume is for the same solid loading ratio. Thus, the heat transfer enhancement due thinner boundary layer becomes larger as the number of particles passing through the boundary layer increases.

Kurosaki et al [8] studied heat transfer experimentally due to axisymmetric impinging jet particles of graphite, glass beads and talcum with different sizes. It was confirmed 
that the effect of disturbing the viscous sublayer with particles augment the heat transfer near a stagnation point to a certain extent but the enhancement approaches an asymptotical value with increasing the loading ratio.

The main purpose of the present work is to study the effect of using the natural sand as solid particles on heat transfer of gas-solid impinging jet from heated flat surface experimentally and numerically. The recent research indicates that sand and dust storms becomes more frequent and are increasing in intensity and strength in Middle East [9] which affect airplanes, power plant, desalination plant, etc. The natural sand was also used in a number of investigations related to jet engine performance which has a significant interest by the military and commercial aerospace industry [10, 11]. The effect of particle size and loading ratio (mass of sand/ mass of air) at different jet velocities on impingement cooling characteristics of flat plate are investigated. Experimental rig is build and used to study the effect of particle size, loading ratio and nozzle-to-plate distance/nozzle diameter ratio on flow and heat transfer. Ansys Fluent is also used to simulate the flow and heat transfer for the same experimental case to validate the model. The numerical model have been used to carry out a parametric study to investigate the effect of the loading ratio, particle diameter and nozzle velocity on the heat transfer at $Z / D=6$.

\section{Experimental facility}

A schematic of the experimental facility for jet impinging system used in this study is shown in Figure 1. The air is supplied by a centrifugal blower (1) through a PVC pipe (2) of $100 \mathrm{~mm}$ in diameter and $1 \mathrm{~m}$ length to the air-sand mixer which controlled by the ball valve (3). The sand particles are fed into the mixer via pipe (5) from the container (6) which controlled by the control valve (7). After the air mixed with the sand, the mixture flows through the pipe (8) of $1.2 \mathrm{~m}$ length and $12 \mathrm{~mm}$ diameter to provide sufficient length/ diameter ratio for fully developed conditions to be achieved. The air-sand mixture flows through the convergent nozzle (9) of $40 \mathrm{~mm}$ length and $10 \mathrm{~mm}$ exit diameter with velocity in range of $20-50 \mathrm{~m} / \mathrm{s}$ towards the heated plate (13). Pitot tube (10) of $0.2 \mathrm{~mm}$ inner diameter connected to a manometer (11) is used to measure the jet velocity. Straight and L-shape Pitot tubes are used to measure the axial and radial velocities of the jet. Pitot tube and the manometer are mounted on a traversing mechanism (12) to be able to move the Pitot tubes in axial and radial directions. 
The target plate (13) is made of stainless steel $(210 \times 210 \times 0.4 \mathrm{~mm})$ fitted with 12 thermocouples (14) of type $\mathrm{K}$ connected to the output recorder (15) to measure the radial temperature distributions. The heater is thermally insulated using a $90 \mathrm{~mm}$ thick layer of polyurethane. A digital multi-meter (16) is used to measure the voltage and current across the resistance of the heater. The front face of the heated plate is facing the impinging jet with a centreline alignment relative to the jet. An AC control unit (17) is used to control the power from AC current source to the heater.

Natural sand particles are used in the experiments which are sifted to reduce the diameter variation with the required particle size. The density of the particles is measured to be $1700 \mathrm{~kg} / \mathrm{m}^{3}$ with heat capacity $800 \mathrm{~kJ} / \mathrm{kg} \mathrm{K}$. Three particles sizes, with mean diameters of 220,350 and $550 \mu \mathrm{m}$ are used in this study.

The total input energy (electrical power) to the heater can be calculated as

$$
q_{\text {total }}=V I
$$

The convection heat transfer from the plate can be written as

$$
q_{\text {conv }}=q_{\text {total }}-q_{\text {loss }}
$$

The heat loss is a combination of radiation and conduction. The radiation is calculated from the plate surface area using the measured temperatures of the plate and the surrounding.

$$
q_{\text {rad }}=\varepsilon A_{S}\left(T_{s}^{4}-T_{\infty}^{4}\right)
$$

Where $€$ : emissivity of plate surface $(0.075)$

The heat loss by conduction is estimated by measuring the surface temperature of the insulating layer by a number of thermocouples embedded at the outer face of the insulation layer. The calculations show that the heat lost by conduction and radiation is about $10 \%$ of the total input energy respectively. The local heat transfer coefficient can be calculated as

$$
h=q_{c o n v} / A_{s}\left(T_{x}-T_{\infty}\right)
$$

The data are also used to calculate the average heat transfer coefficient (hav) for the whole plate by averaging the local values. The local and average Nusselt numbers can be calculated as 


$$
N u=\frac{h D}{k_{f}} \quad \text { and } \quad N u_{a v}=\frac{h_{a v} D}{k_{f}}
$$

To assess the accuracy of the experimental data, a single phase flow experiments are carried out to obtain the Nusselt number distribution for jet velocity $=47 \mathrm{~m} / \mathrm{s}$ and $Z / D=6$. Figure 2 shows a comparison between the present experimental measurements and data from literature $[12,13,14]$. In the stagnation region, there is a significant discrepancy in Nusselt number; particularly the data from [14] which is higher than the present work by about $65 \%$ but the difference becomes smaller compared to other researchers. The comparison also shows that the discrepancy is gradually decreases in radial direction compared to the stagnation point. The results from the simulation are also included in Figure 2 which shows a reasonable agreement with experimental measurements. The results of comparison reflect the reliability of both experimental measurements and CFD model and to extend the work for two-phase flow study.

\section{CFD Model and Simulation}

\subsection{Description of Computational Domain and Boundary Conditions}

Figure 3 shows the 3 -dimensional computational domain created for jet flow vertically from the nozzle into unconfined space, limited by the heated plate (wall) and constant pressure outlet. The computational domain has the dimensions of half of the experimental domain due to the geometry and thermal symmetries. Three inlet velocities of 15.32 .5 and $47 \mathrm{~m} / \mathrm{s}$ are used. The diameter of the nozzle is $10 \mathrm{~mm}$ while $Z$ values changed from $20 \mathrm{~mm}$ to $80 \mathrm{~mm}$. A constant heat flux boundary condition is taken from experimental data. The fluid properties used in the simulation are evaluated at the mean film temperature $\left[\left(T_{s}+T_{\infty}\right) / 2\right]$ for each experimental case. The convergence criterion of $10^{-5}$ for continuity, velocity components, and energy and turbulence quantities is used.

\subsection{Mathematical Formulation}

\subsubsection{Gas Phase}

The equations for conservation of mass, momentum with an appropriate turbulence model and thermal energy equation [15] are used. The model was devised for 3- 
dimensional, steady, turbulent, incompressible, and axisymmetric with constant properties.

Continuity equation

$$
\frac{\partial\left(\rho u_{i}\right)}{\partial x_{i}}=S_{m}
$$

$\underline{\text { Momentum equations }}$

$$
\frac{\partial\left(\rho u_{i} u_{j}\right)}{\partial x_{j}}=-\frac{\partial p}{\partial x_{i}}+\frac{\partial}{\partial x_{j}}\left[\mu\left(\frac{\partial u_{i}}{\partial x_{j}}+\frac{\partial u_{j}}{\partial x_{i}}\right)\right]+\frac{\partial\left(-\rho \overline{u_{i}^{\prime} u_{j}^{\prime}}\right)}{\partial x_{j}}+\rho g+F
$$

Reynolds stresses in the Eq. 7 is modelled using Boussinesq approximation [15] (2010):

$$
\frac{\partial\left(-\rho \overline{u_{i}^{\prime} u_{j}^{\prime}}\right)}{\partial x_{j}}=\mu_{t}\left(\frac{\partial u_{i}}{\partial x_{j}}+\frac{\partial u_{j}}{\partial x_{i}}\right)-\frac{2}{3} \rho k \delta_{i j}
$$

Where $\mathrm{i}$ or $\mathrm{j}=1$ correspond to the $\mathrm{x}$-direction, $\mathrm{i}$ or $\mathrm{j}=2$ the $\mathrm{y}$-direction and $\mathrm{i}$ or $\mathrm{j}=3$ the z-direction. $\delta_{i j}$ is kronecker delta $\left(\delta_{i j}=1\right.$ if $\left.\mathrm{i}=\mathrm{j}\right)$

Energy equation

$$
\frac{\partial\left(u_{i} \rho E\right)}{\partial x_{j}}=\frac{\partial}{\partial x_{j}}\left[\left(\kappa_{f}+\frac{c_{p} \mu_{t}}{\operatorname{Pr}_{t}}\right) \frac{\partial T_{i}}{\partial x_{j}}\right]+S_{h}
$$

In order to solve the mass, momentum and energy equations, it is necessary to model the interfacial forces, Reynolds stresses and the heat exchange term. The interfacial forces models are used to evaluate the pressure and viscous stresses at the interface which includes drag, lift and virtual mass forces. The turbulent stresses appearing in the momentum equation are evaluated using a turbulence model. The heat transfer equation from continuous to discrete phase is used. ANSYS Fluent 14.7 is used to solve the mass, momentum and energy equations incorporating the interface forces models, the RNG $k-\varepsilon$ turbulence model with the scalable wall function and heat transfer equation at the air-particle interface. 
Turbulent viscosity

$$
\mu_{t}=\frac{\rho C_{\mu} k^{2}}{\varepsilon}
$$

In present study, the RNG k- $\varepsilon$ turbulence model [16] is applied by considering the studies of Pulat et al [17] and Heck et al [18]. They found that this model is suitable to simulate the impinging jet flow in stagnation zone and wall jet regions adequately. The equations for the turbulent kinetic energy $k$ and the dissipation rate $\varepsilon$ are:

\section{$\underline{\text { Turbulence kinetic energy, } k}$}

$$
\rho \frac{\partial}{\partial x_{i}}\left(k u_{i}\right)=\frac{\partial}{\partial x_{j}}\left(\alpha_{k} \mu \frac{\partial k}{\partial x_{j}}\right)+G_{k}-\rho \varepsilon
$$

Dissipation rate of turbulent kinetic energy, $\varepsilon$

$$
\rho \frac{\partial}{\partial x_{i}}\left(\varepsilon u_{i}\right)=\frac{\partial}{\partial x_{j}}\left(\alpha_{\varepsilon} \mu \frac{\partial \varepsilon}{\partial x_{j}}\right)+C_{1 \varepsilon} \frac{\varepsilon}{k} G_{k}-C_{2 \varepsilon} \rho \frac{\varepsilon^{2}}{k}-R_{\varepsilon}
$$

Where

$$
G_{k}=\mu_{t} S^{2}, S=\sqrt{2 S_{i j} S_{i j}}, S_{i j}=\frac{1}{2}\left(\frac{\partial u_{j}}{\partial x_{i}}+\frac{\partial u_{i}}{\partial x_{j}}\right), R_{\varepsilon}=\frac{C_{\mu} \rho \eta^{3}\left(1-\eta / \eta_{o}\right)}{1+\beta+\eta^{3}} \frac{\varepsilon^{2}}{k}, \eta=S \frac{k}{\varepsilon}
$$

$G_{k}$ is the turbulence kinetic energy due to the mean velocity gradients. The model constants are given by Yakhot and Orszag [16] and Launder and Spalding [21]: $C_{\mu}=$ $0.09, C_{1 \varepsilon}=1.42, C_{2 \varepsilon}=1.68, \alpha_{k}$ and $\alpha_{s}$ are constant and equal to $1.393, \eta_{o}=4.38$ and $\beta=0.012$.

\subsubsection{Particle equation}

Prediction of the particle trajectory is based on integrating the force balance on the particle, which is based on the Lagrangian formulation [7, 19]. The force balance of inertia force, drag force and gravitational force acting on the particle in the $x$ direction as [15]:

$$
\frac{d u_{i p}}{d t}=F_{D}\left(u_{i}-u_{i p}\right)+\frac{g_{i}\left(\rho_{p}-\rho\right)}{\rho_{p}}
$$

Where $F_{D}\left(u_{i}-u_{i p}\right)$ is the drag force per unit particle mass and drag force $\left(F_{D}\right)$ 


$$
F_{D}=\frac{18 \mu}{\rho_{p} d_{p}^{2}} \frac{C_{D} \operatorname{Re}}{24}
$$

Where, $\mathrm{u}$ is the air velocity, $C_{D}$ the drag coefficient, $u_{p}$ is the particle velocity, $\mu$ is the air viscosity, $\rho$ is the air density, $\rho_{p}$ is the particle density and $d_{p}$ is the particle diameter. $\mathrm{Re}$ is the relative Reynolds number which is defined as:

$$
\operatorname{Re}=\frac{\rho d_{p}\left|u_{i p}-u_{i}\right|}{\mu}
$$

The particle interaction with wall can be set in Fluent as reflect, trap, escape, wall-jet and interior. The wall-jet and reflect wall boundary conditions are used in this study to describe the particle behaviour after its collision with the wall.

In addition to the general model formulation, the near-wall treatment can affect the accuracy of the results where the hydrodynamics and thermal boundary layers are evolved. The wall function approach is used to simplify the solution of turbulent flow close to the wall [14]. The simplifications and economies provided by wall function make them widely used in the application of commercial CFD codes to compute the complex turbulent flow problems [15]. The flow can be divided into two regions; viscous sublayer close to the wall and a fully developed turbulent region at some distance from the wall. The scalable wall function available in Fluent assumes that the start of turbulent region coincides with edge of viscous sublayer $\left(\mathrm{y}^{+}\left(\mathrm{yU}_{\mathrm{T}} / v\right) \approx\right.$ $11.26[20]$ is used in this study due the difficulty of achieving high values $(y+>30)$ at the stagnation point when standard option is used.

\subsubsection{Grid Independence}

The grid independence investigation is performed using the RNG $k-\varepsilon$ turbulence model to obtain grid independent results. Three different mesh sizes are used for $\mathrm{Z} / \mathrm{D}=6$ and $\mathrm{UJ}_{\mathrm{J}}=47 \mathrm{~m} / \mathrm{s}(\mathrm{Re}=31143)$ to investigate the variation in Nusselt number. Figure $4 a$ shows the Nu distributions of predicted and experimental results $\mathrm{Nu}$ for different cells sizes. The local values show small differences at stagnation zone. Comparing the average Nu show that the value increased from 44.5 to 46.4 (cells number $=603421$ and 1001535 ) which is about $4.1 \%$. The cell volume of 0.00341 $\mathrm{m}^{3}$ (cells number $=603421$ ) is chosen as the predicted values of $\mathrm{Nu}$ are lesser deviation from the experimental measurements. This is the cell volume is used for all further studies to generating the mesh of the computational domains. 


\section{Results and Discussions:}

\subsection{Turbulence Models Study}

In addition to the RNG k- $\varepsilon$ turbulence model as recommended by Pulat et al [17] and Heck et al [18] to simulate the impinging jet flow in stagnation zone and wall jet regions, one simulation for the selected number of cells (622765) has been carried out using the standard $k-\varepsilon$ and SST $k-\omega$ models to confirm the advantage of using RNG k- $\varepsilon$ over the other models. Figure $4 b$ presents the Nu for Z/D $=6$ from different turbulence models. The results show that for the standard $k-\varepsilon$, the Nu value is higher by $6 \%$ at the stagnation point compared to experimental Nu value but become $3.8 \%$ and $27 \%$ less than experimental for SST k- $\omega$ and RNG $k-\varepsilon$ respectively. The average values of standard $k-\varepsilon$, SST $k-\omega$ and RNG $k-\varepsilon$ are $49.6,48.5$ and 444.5 respectively which is closed to the experimental data (47.38). From the average and radial distribution, it can be concluded that RNG $\mathrm{k}-\varepsilon$ model is more appropriate to be used in this study. The discrepancy between the Nu from different turbulence models can be attributed to the difference in the structure of the turbulent intensity (TI) as shown in Figure 4c. The results in Figure 4c show that standard k- $\varepsilon$ model gives the highest values of turbulence intensity in stagnation zone compared to SST $k-\omega$ and RNG $k-\varepsilon$ model respectively. The present conclusion is in consistent with previous published work $[13,14]$.

\subsection{Effect of Z/D ratio on Heat transfer for single and two phase flow}

Figure $5 a$ presents the effect of Z/D ratio on heat transfer rate for jet velocity $=47$ $\mathrm{m} / \mathrm{s}$. This is crucial in designing to design the equipments using the jet impinging cooling. The results from predictions are in good agreement with experimental data for $r / D>1$ but there is some discrepancy at the stagnation zone. The experimental measurements demonstrate that Nusselt number has a maximum value at the stagnation point for $Z / D=4$, but the predictions show that Nusselt number continue to increase with $Z / D$ ratio for all the cases investigated in this study. Figure $5 b$ present the effect of $Z / D$ ratio on Nusselt number with loading ratio $\Gamma=1.38$ compared to single phase values. The results show that the difference between the loaded and single phase flow increased with higher Z/D values at the stagnation point. This may be attributed to the in particle slip velocity for higher Z/D values. The results also 
show that the Local Nusselt number for loaded cases has a minimum value at Z/D = 6. This minimum value can be explained by the corresponding minimum value of turbulence intensity from contours given in Figure $5 \mathrm{c}$. The minimum turbulence intensity at $Z / D=6$ may be attributed to the change in the jet spreading and the low gas velocity near the plate surface due to the existence of particles [4].

\subsection{Two phase flow investigation}

Figure 6a shows the radial profiles of the experimental and numerical Local Nusselt number for single and two-phase flow jet at $Z / D=6, d_{p}=220 \mu \mathrm{m}$ and jet velocity $=$ $47 \mathrm{~m} / \mathrm{s}$. Three loading ratios are used to understand its effect on Local Nusselt number. The experimental results show that the Local Nusselt number decreased by about $11 \%$ at stagnation point for loading ratio, $\Gamma=0.18$, but increasing $\Gamma$ further have insignificant effect. On the other hand, for $r>3 \mathrm{~cm}(r / D>3)$, there is virtually little change of local Nusselt number in comparison to single phase flow. A similar behaviour was observed by Takehiko et al [2] when they used glass beads as solid particles. They conducted a special experiment on observing wear due to erosion on the surface to confirm the collision of the particles with surface. They found that the glass beads particles have no effect on heat transfer from the surface. They explained this behaviour as follows: the glass beads particles suspend or fly relatively far after rebounding from the surface and disrupt the incoming eddies from the nozzle which suppresses the turbulence development. The experimental and prediction are in good agreement.

In attempts to explain the significant change in Local Nusselt number at stagnation zone $(r / D<3)$ compared to the outer zone $(r / D>3)$, the boundary layer development was investigated by measuring the velocity profiles at four radial positions on the plate from the stagnation as given in figure $6 \mathrm{~b}$. The steep change in velocity distribution at $r / D=1$ is very clear that compared to other $r / D$ ratios which lead to higher turbulence fluctuations and higher $\mathrm{Nu}$ at stagnation zone. The other interesting noticeable difference is the velocity distribution and thickness of boundary between the single and two phase flow at $r / D=1$ and 3 which may lead to the larger difference in Local Nusselt Number at stagnation zone compared to outer zone.

Figure $7 a$ presents another case with $Z / D=2, d_{p}=350 \mu \mathrm{m}$ and jet velocity $=32.5$ $\mathrm{m} / \mathrm{s}$. The results show a similar behavior to the case of $Z / D=6, d_{p}=220 \mu \mathrm{m}$ and jet 
velocity $=47 \mathrm{~m} / \mathrm{s}$. However, the difference of Local Nusselt between the single and two-phase flow is smaller for both experimental and numerical results. This may attributed to lower jet velocity and the early stage of jet development where the effect of particle on the two phase flow turbulence is insignificant as discussed in section 4.3. A similar results was observed by Yoshida et al [4] for low jet velocity $=15 \mathrm{~m} / \mathrm{s}$.

Figure $7 \mathrm{~b}$ present the boundary layer development at 3 radial positions on the plate from the stagnation point as given in figure $6 \mathrm{~b}$. The velocity distributions show no difference between single and two phase leading to same boundary layer thickness which result in small difference of Local Nusselt number.

The main difference between the experimental and numerical results in Figures $6 a$ and $6 \mathrm{~b}$ is the location of the peak values from the stagnation point and the difference in the shapes of local Nu profiles. However, the average values are in good agreement.

\subsection{Parametric study}

The model is used to investigate the influence of particle velocity, loading ratio and particles diameters on heat transfer from the heated plate. Figures $8 \mathrm{a}, 8 \mathrm{~b}$ and $8 \mathrm{c}$ present results for jet velocity $=15 \mathrm{~m} / \mathrm{s}$ and three particles diameters of 220, 350 and $550 \mu \mathrm{m}$ for different loading ratios. The two different behaviours of particles reported in literature of rebounding (reflection) and the formation of layer on the heated surface (wall jet) on Local Nusselt number are investigated. For same particle diameter, the results demonstrate that increasing loading ratio increases the Local Nusselt number when wall jet option is used but using the reflect option (particle rebounding) decreases the Local Nusselt number. These results are supported by the experimental data from Takehiko et al [2] for glass beads (rebounding particles/ reflection) and graphite (wall jet/ layer).

The effect of loading ratio is also investigated in the range of $0-7 \mathrm{~kg}$ of sand/ $\mathrm{kg}$ of air. The results show that increasing loading ratio increases/decreases the Local Nusselt number based on the selected option of the particles behaviour for all diameters. It can be observed that the increase/decrease of Local Nusselt number become smaller at larger particle diameters. However, increasing the loading ratio increase the Local Nusselt number up to a certain value but the rate of change 
decrease for higher loading ratios. This behaviour was also observed experimentally by other researchers (Takehiko et al [2], Kurosaki et al [8]).

Comparing the Nusselt numbers from Figures $8 \mathrm{a}, 8 \mathrm{~b}$ and $8 \mathrm{c}$ show that the values are decreased for larger particles. Jin-song et al [7] reported a similar trend when ash particle diameter increased which was attributed to the smaller number of the particles per unit volume for the same particles loading ratio.

Figure 9 gives the summary of the of average Nusselt number for different particle diameters, loading ratios. In addition to results for jet velocity $=15 \mathrm{~m} / \mathrm{s}$, Nu was also predicted for jet velocity $=47 \mathrm{~m} / \mathrm{s}$. A similar trend of Local Nusselt numbers can be observed for both velocities.

\section{Conclusions}

Experimental and numerical results for gas-solid flow using natural sand are presented. In general, the introducing the sand particles reduces the Local Nusselt number values at the stagnation zone $(r / D<2)$ compared to single phase flow. The main conclusions from this study can be summarized as:

- For single phase flow, the experimental and predictions results show that Local Nusselt number increases with Z/D. For two-phase flow, the CFD model is used to produce Local Nusselt number data at different Z/D ratio which indicate the minimum value at $Z / D=6$. The corresponding turbulence intensity contours from predictions at different $Z / D$ ratios show that the turbulence intensity also has a minimum value at $Z / D=6$.

- There is a strong correlation between the velocity distribution for both single and two-phase flow in the boundary layer on the plate and the Local Nusselt number values. The higher velocity gradient at $r / D$ leads to higher turbulence intensity and higher Nusselt numbers and vice versa.

- For reflection particle behaviour, introducing the natural sand particles into single phase flow demonstrate a steep decrease in Local Nusselt number due to the suppression of turbulence intensity. For wall-jet particle behaviour, The Local Nusselt number increase gradually with increasing loading but a small increase observed for loading ratio $>7$. 
- The single and two-phase flow experimental results are compared well with predictions when the particle reflection option is used in the simulation. The discrepancy in the local values near the stagnation point can be attributed to the complicated nature of the flow with additional influence of particles sand particles reflection in at different angles.

\section{References}

[1] N. Zuckerman, N. Lior, Advances in Heat Transfer 2006, 39, 565.

[2] T. Yokomine, A. Shimizu, A. Saitoh, K. Higa, Experimental Thermal and Fluid Science 2002, 26, 617.

[3] A. Shimizu, R. Echigo, S. Hasegawa, "Impinging jet heat transfer with gas-solid suspension medium," Advances in Enhanced Heat Transfer, Proceedings of the 18th National Heat Transfer Conference ASME, 155-160, 1979.

[4] H. Yoshida, K. Suenaga, R. Echigo, Int. J. Heat Mass Transfer 1990, 33, 859.

[5] T. Yokomine, A. Shimizu, Experimental investigation on impingement heat transfer of gas-solid suspension flow, Proc. 5thASME/JSME Therm. Eng. Conf. 1-7, 1999.

[6] A. Shimizu, T. Yokomine, S. Hasegawa, T. Kunugi, Y. Seki, Impinging heat transfer enhancement of dense gas-solid suspension flow, Proc. ASME/JSME Therm. Eng. Conf. 143-148, 1995.

[7] Z. Jin-song, L. Zhonh-yang, G. Xiang ,N. Ming-Jiang, C. Ke-Fa, Effect of particle loading ratio on heat transfer enhancement in a gas-solid suspension cross flow, (Institute for Clean Energy and Environmental Engineering Key Lab of Ministry of Education, Thermal Power Engineering , Zhejiang University , Hangzhou 310027, China, 2002.

[8] Y. Kurosaki, T. Murasaka, I. Satoh, T. Kashiwagi, Study on Heat Transfer Mechanism of A Gas-Solid Suspension Impinging Jet (Effect of particles and thermal properties), $8^{\text {th }}$ International Heat Transfer conference, vol. 5, pp2587 -2592, Hemisphere Pub Corp., Washington, 1986.

[9] http://www.thenational.ae/arts-culture/destructive-sandstorms-in-middle-easttopic-of-un-task-force.

[10] K. Brun, M. Nored, R Kurz, J. Eng. Gas Turbines Power 2012, 134 (1), 012402

[11] S. Singh, D. Tafti, Int. J. Heat and Fluid Flow 2015, 52, 72 
[12] M. Attalla, M.S. Ahmad, Int. J. systems Applications, Engineering \& Development 2012, 6, 376.

[13] H. M. Hofmann, M. Kind, H. Martin, Int. J. Heat Mass Transfer 2007, 50, 3957.

[14] R. J. Goldestien, A. I. Behbahani, Int. J. Heat Mass Transfer 1982, 25, 1377.

[15] ANSYS Fluent, http://www.ansys.com/Industries/Acaemic/Tools/Citations

[16] Yakhot, V., and Orszag, S. A., I. Basic Theory. J. Scientific Computing, 1986, 1, 1.

[17] E. Pulat, M. Kemal, I. A. B. Etemoglu, M. Can, Numerical Heat Transfer, Part B 2011, 60, 486.

[18] U. Heck, K. Fritsching, K. Bauckhage, Int. J. Numer. Methods Heat Fluid Flow 2001, 11, 36.

[19] M. B. Stakic, G. S. Z ivkovic, M. A. Sijercic, Int. J. Heat Mass Transfer 2011, 54, 2262.

[20] C. L. V, Jayatilleke, "The influence of Prandtl Number and Surface Roughness on the Resistance of the Laminar Sublayer to Momentum and Heat Transfer," Prog. Heat Mass Transfer 1, 193 (1969)

[21] B. E. Launder, D. B. Spalding, Lectures in Mathematical Models of Turbulence, Academic Press, London, 1972 


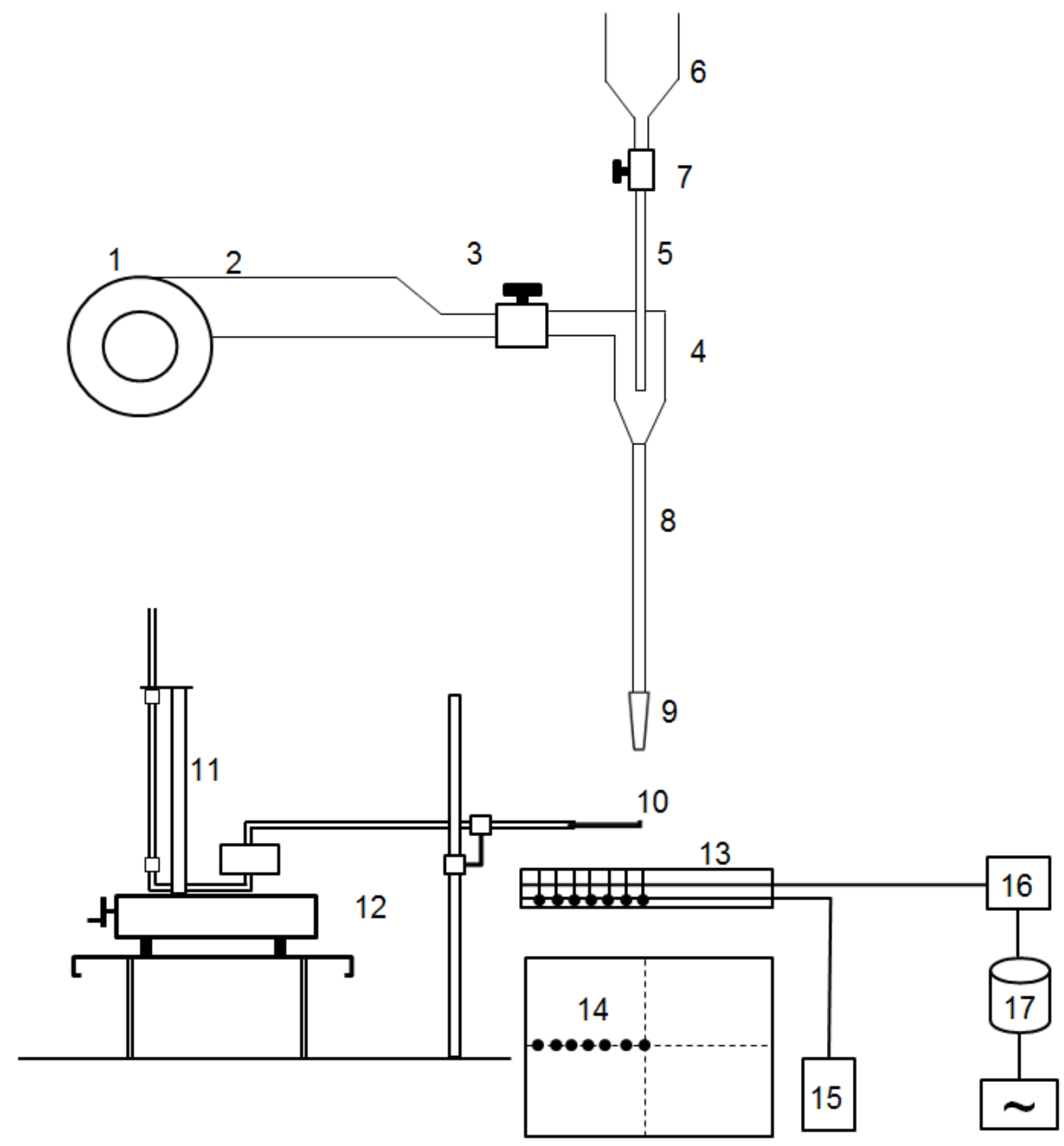

(1) Centrifugal blower, (2) PVC pipe, (3) Ball valve, (4) Air-sand mixer, (5) Sand supply pipe, (6) Sand container, (7) sand control valve, (9) nozzle, (8) injection pipe, (10) Pitot tube, (11) manometer, (12) Traversing Mechanism , (13) target plate, (14) thermocouples, (15) temperature recorder (16) digital multi-meter, (17)controller

Figure 1.The schematic diagram of experimental facility. 


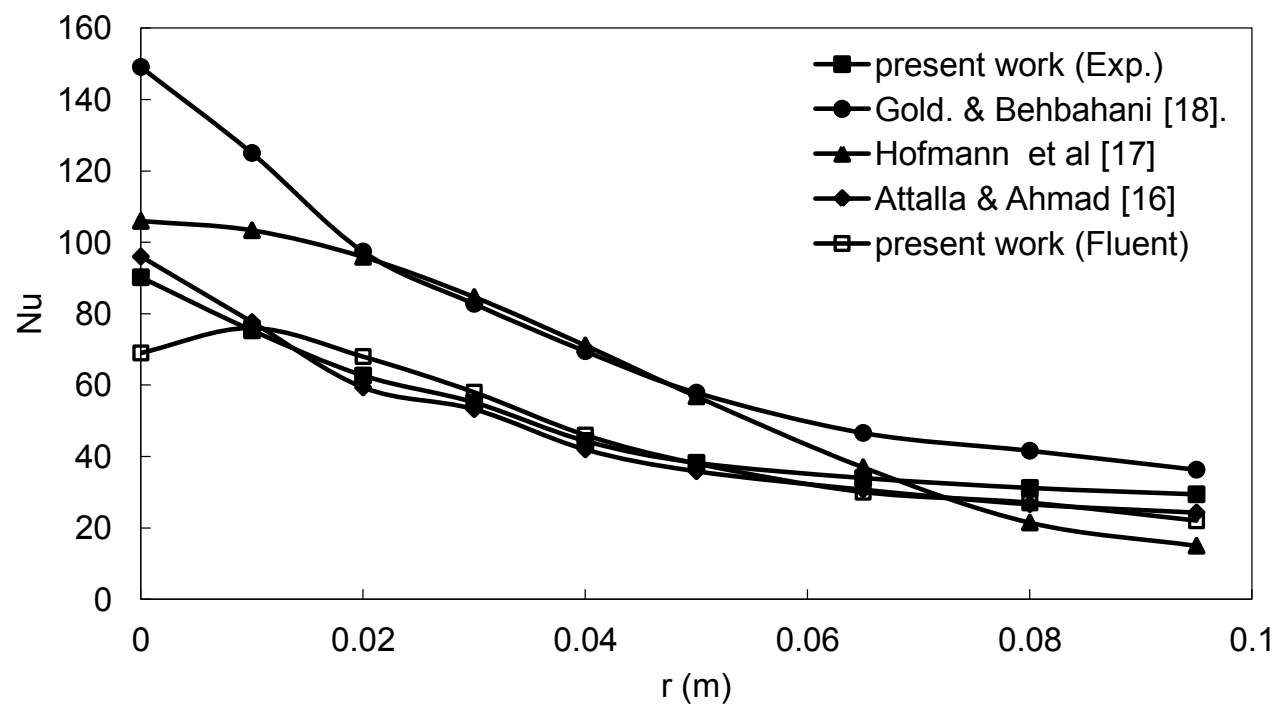

Figure 2. comparison of present work with data from literature $\left(U_{J}=47 \mathrm{~m} / \mathrm{s}(\operatorname{Re}=31500), \mathrm{Z} / \mathrm{D}=6\right)$.

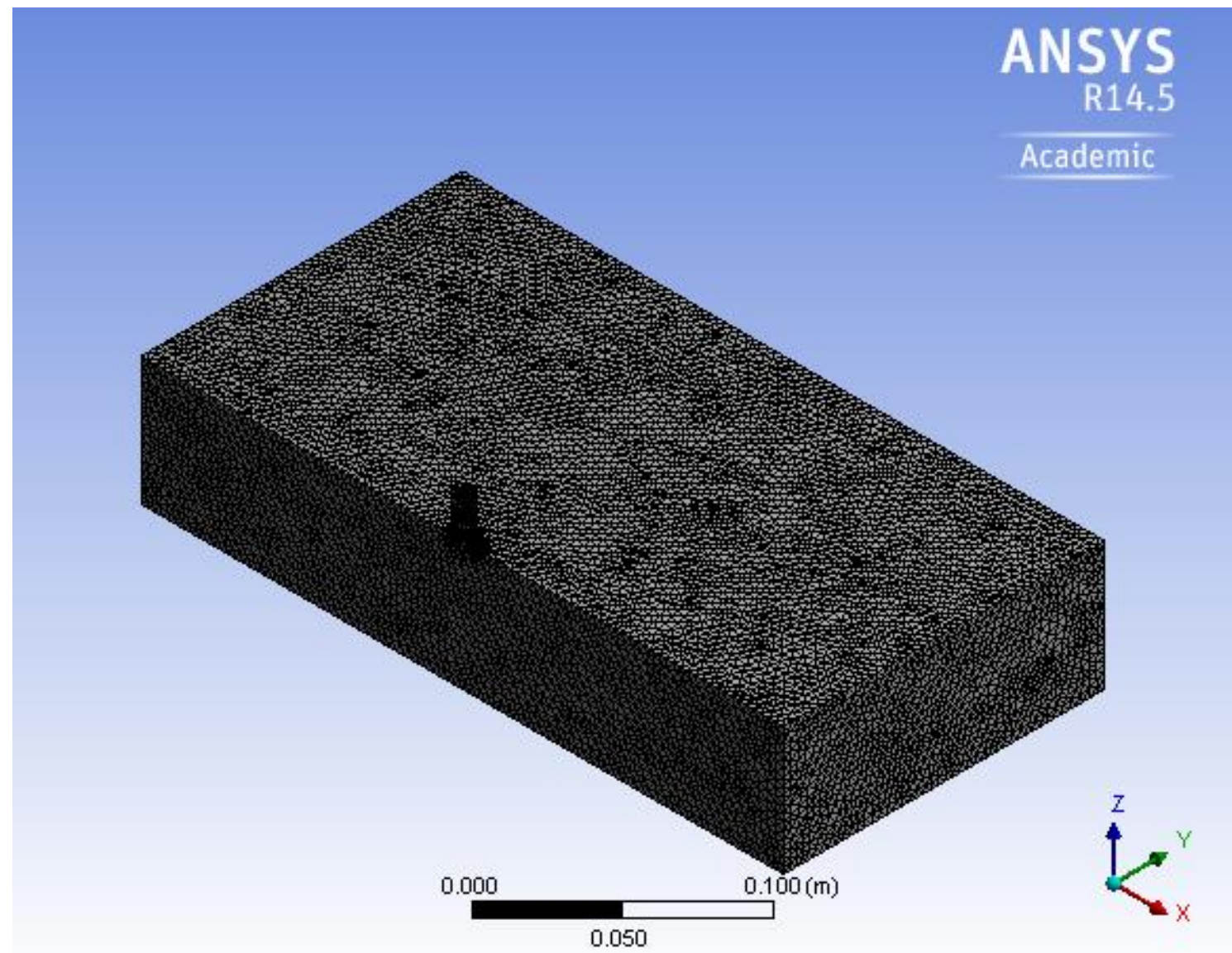

Figure 3a. 3-D Computational domain 


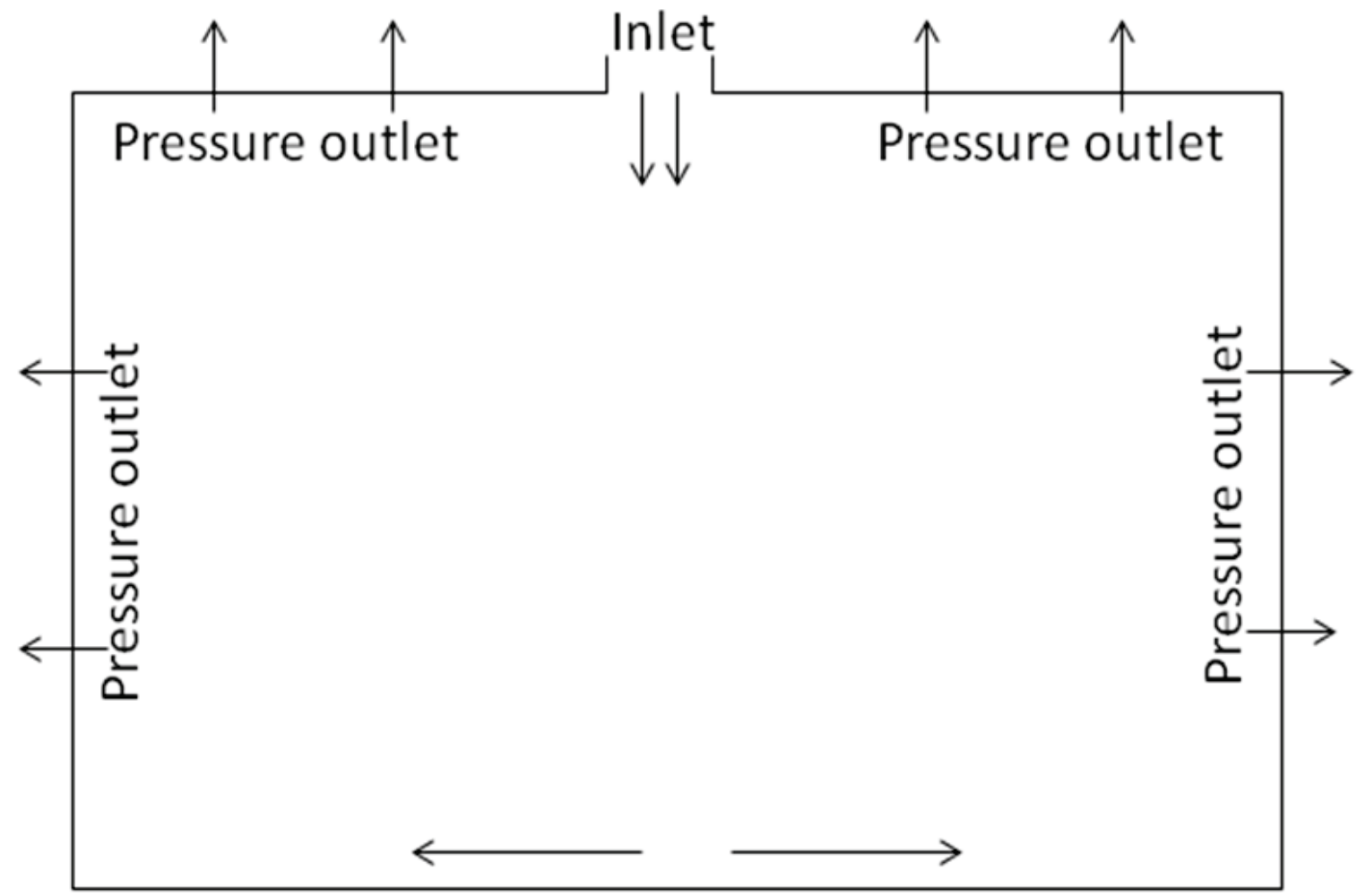

Target plate

Figure 3b. 2-D computational domain with applied boundary condition

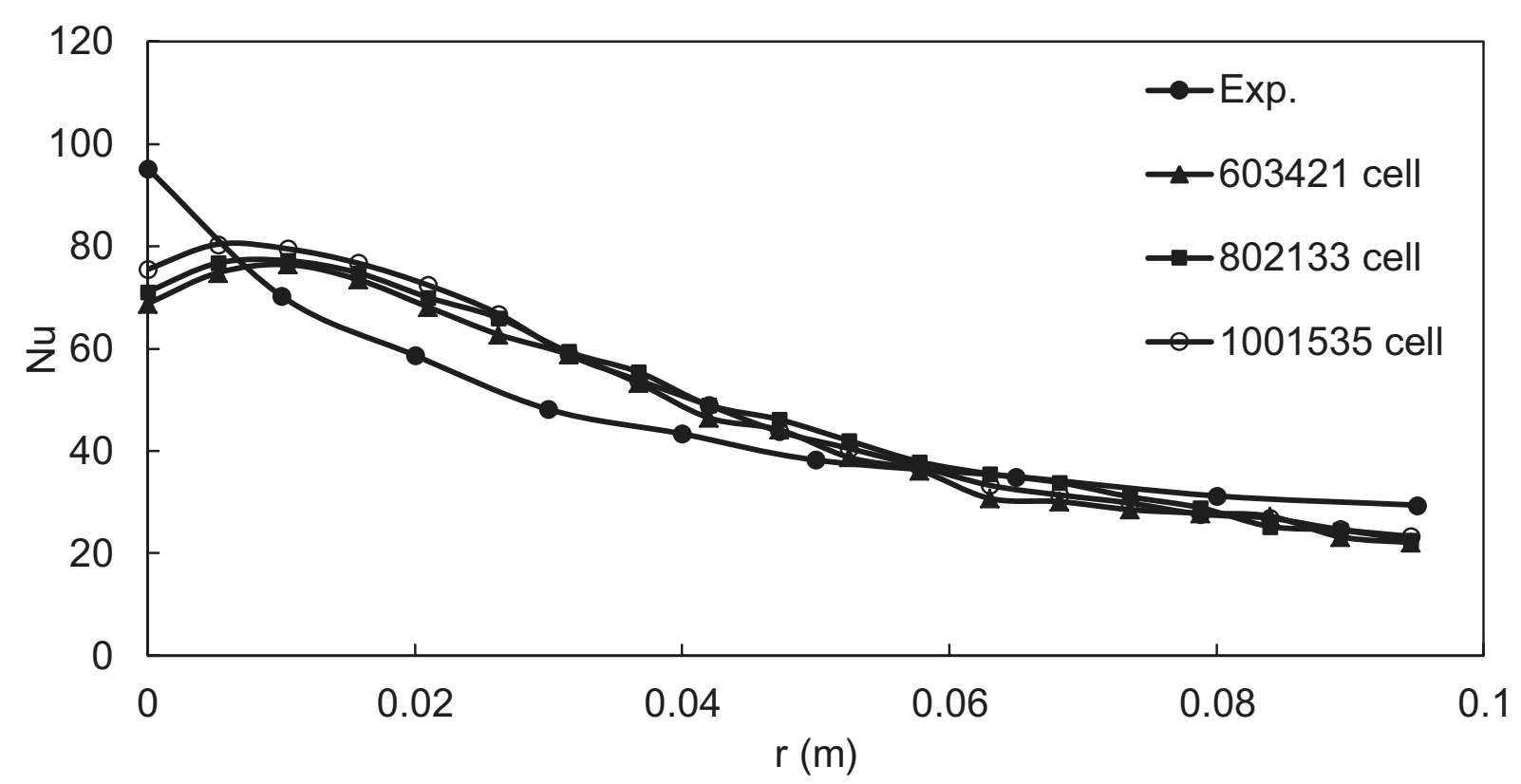

Figure 4a. Effect of number of elements on local Nusselt number $\left(U_{J}=47 \mathrm{~m} / \mathrm{s}, \mathrm{Z} / \mathrm{D}=6\right)$. 


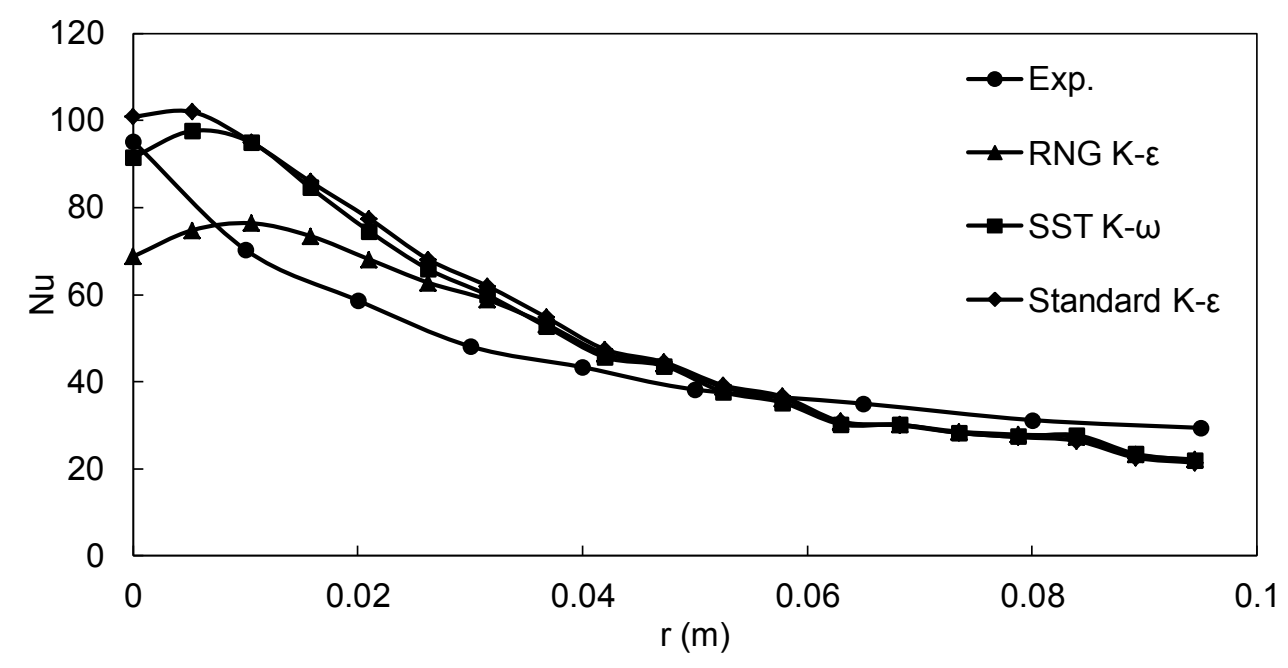

Figure 4b. Local Nusselt number distribution for different turbulence models $\left(U_{J}=47 \mathrm{~m} / \mathrm{s}, \mathrm{Z} / \mathrm{D}=6\right)$.

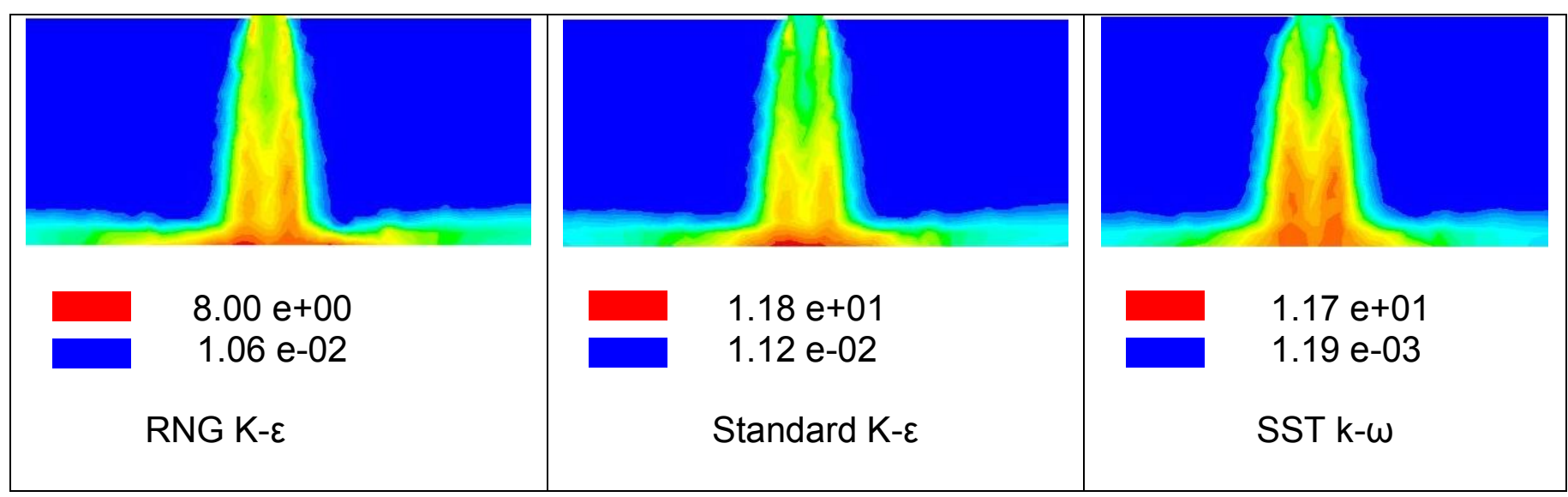

Figure 4c. Turbulence intensity contours for different turbulence models $\left(U_{J}=47 \mathrm{~m} / \mathrm{s}, \mathrm{Z} / \mathrm{D}=6\right)$. 


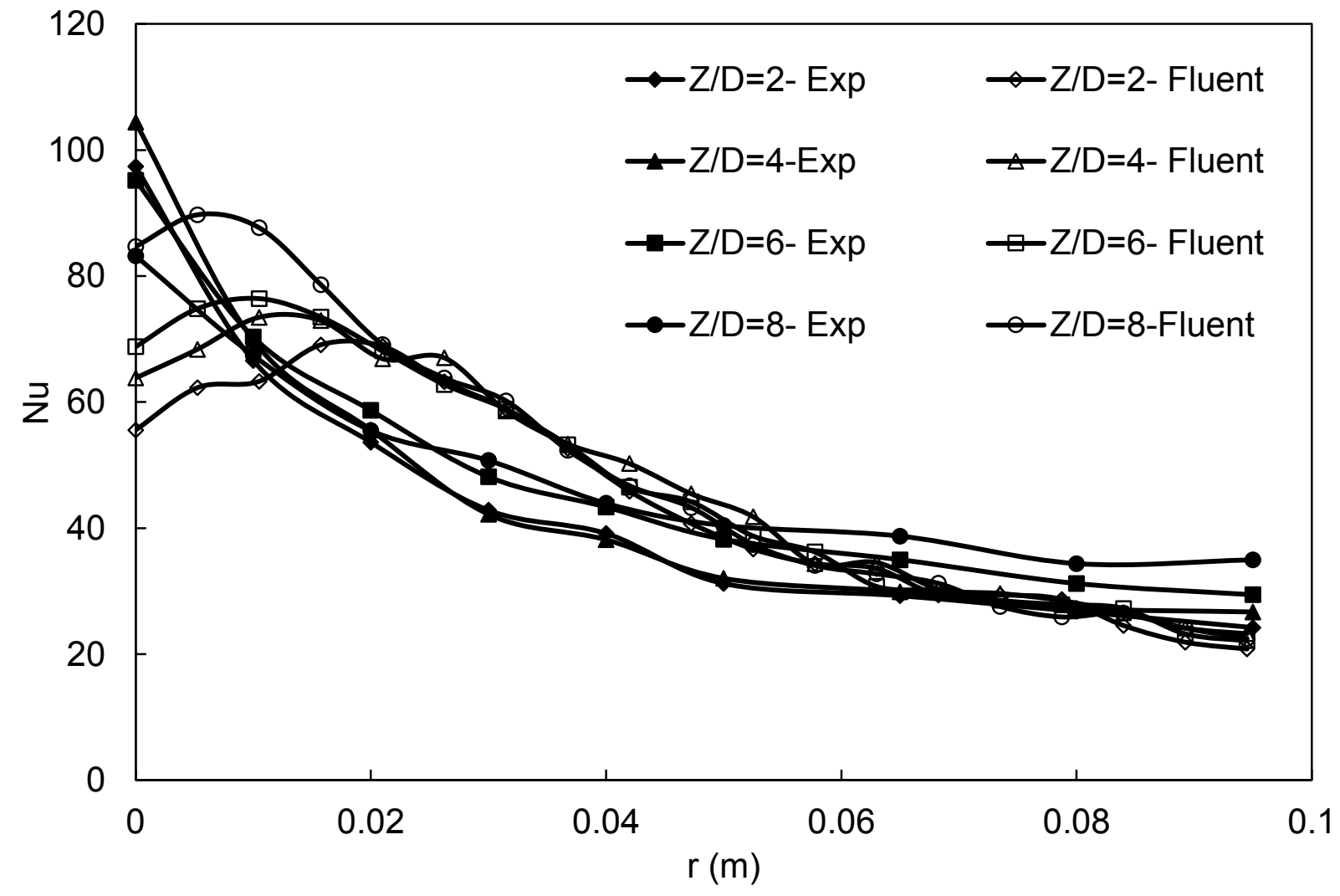

Figure 5a. Effect of Z/D ratio on local Nusselt number for single phase flow $\left(U_{J}=47 \mathrm{~m} / \mathrm{s}\right)$. 


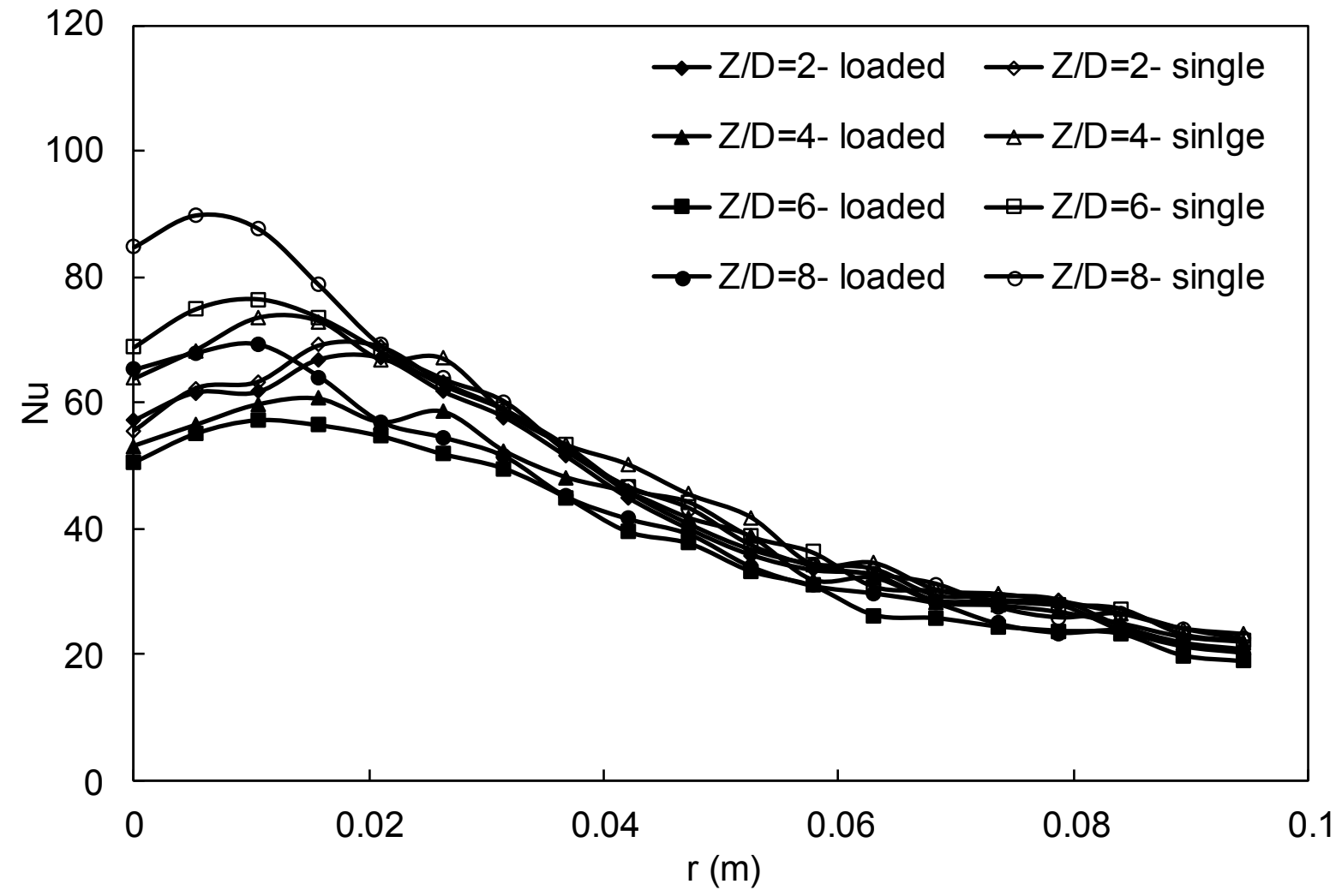

Figure $5 b$. Effect of Z/D ratio on local Nusselt number from CFD for single phase and two-phase flow. $\left(U_{J}=47 \mathrm{~m} / \mathrm{s}, d_{p}=350 \mu \mathrm{m}, \Gamma=1.38\right.$, reflect). 


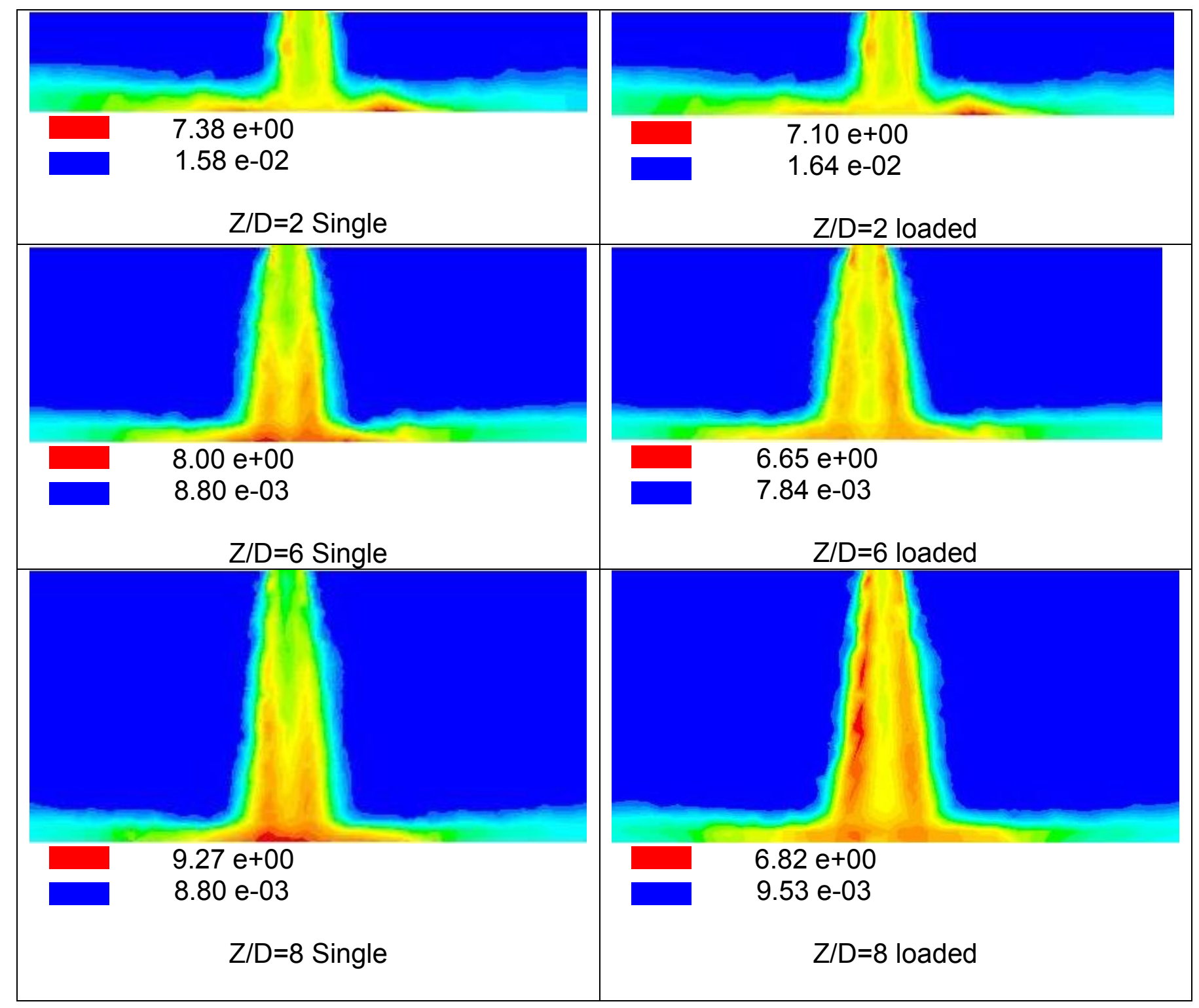

Figure $5 c$. Effect of Z/D ratio on turbulence contours for single phase and two-phase flow. $\left(U_{J}=47 \mathrm{~m} / \mathrm{s}, d_{p}=350 \mu \mathrm{m}, \Gamma=1.38\right.$, reflect). 


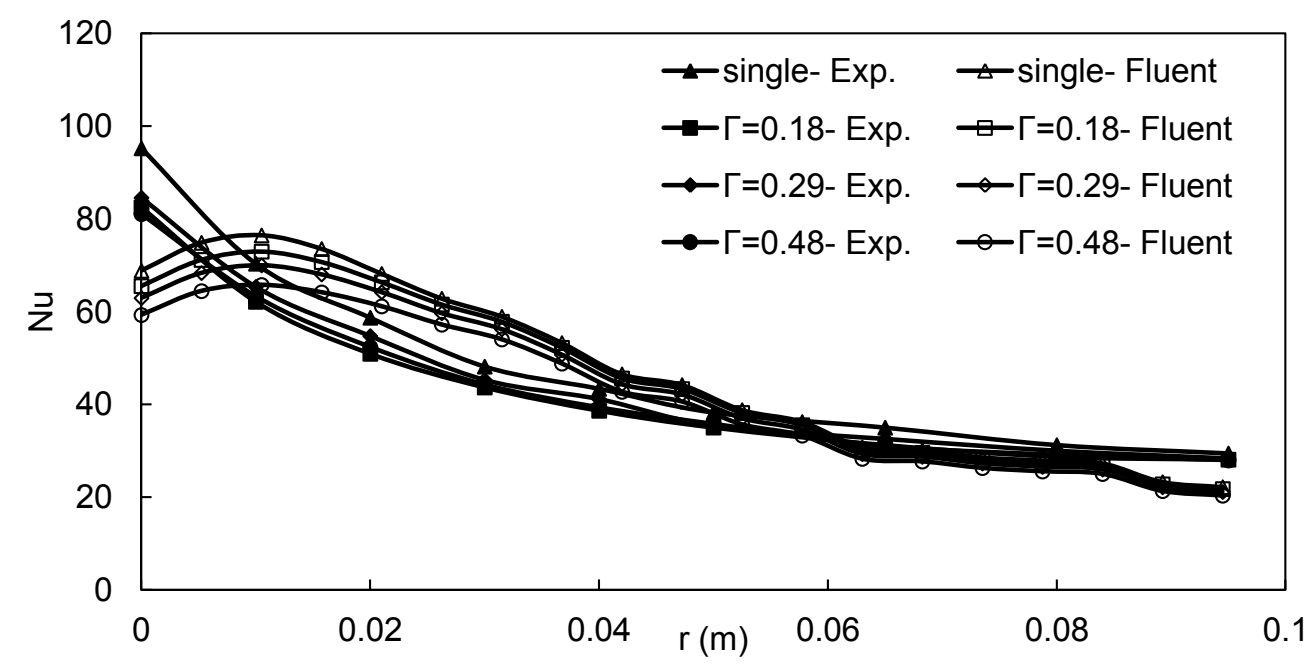

Figure 6a. Comparison of experimental Nusselt number with predictions for different loading ratios $\left(U_{J}=47 \mathrm{~m} / \mathrm{s}, Z / D=6\right.$, $\left.\mathrm{d}_{\mathrm{p}}=220 \mu \mathrm{m}\right)$

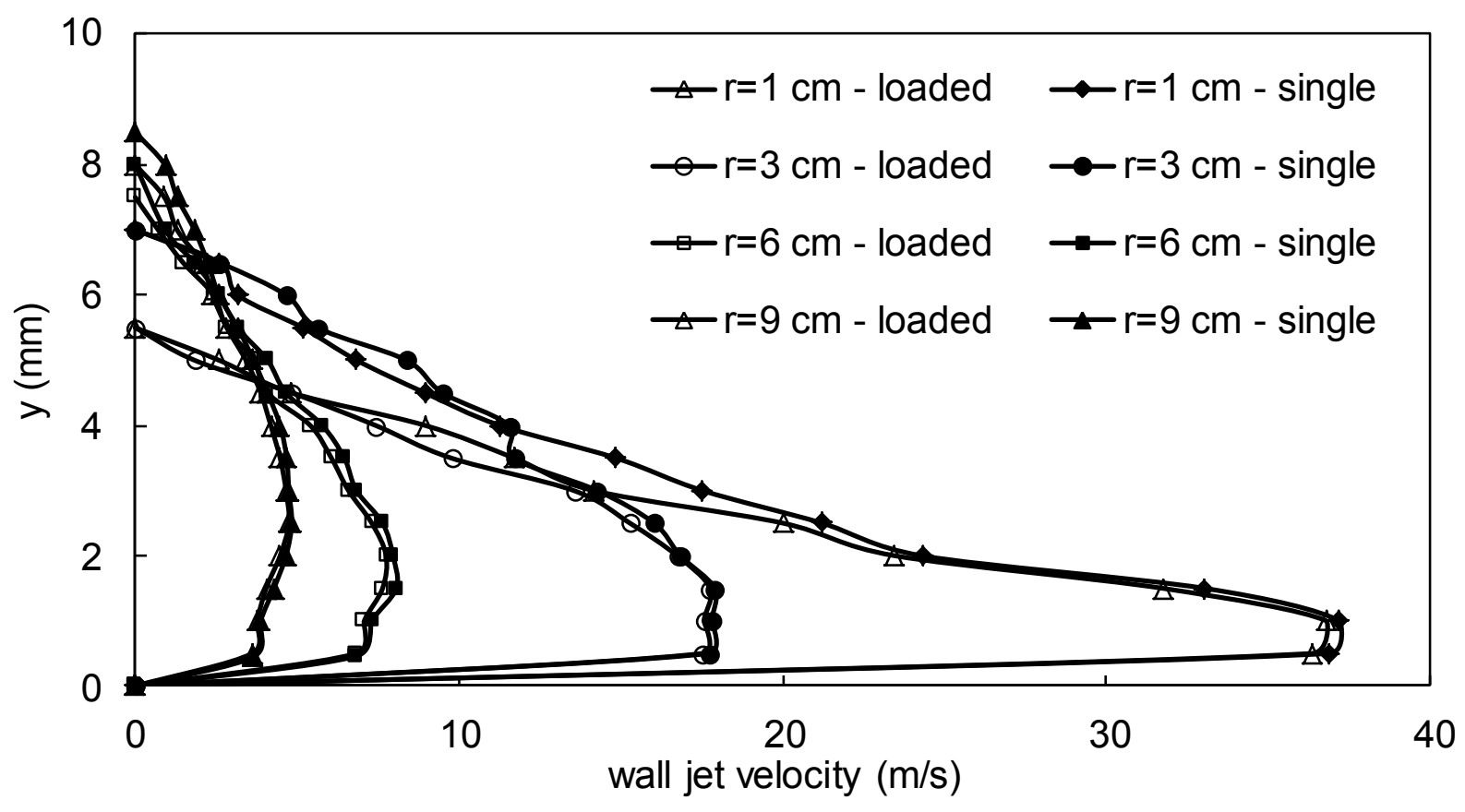

Figure $6 \mathrm{~b}$. Boundary layer development for single and two-phase flow $\left(U_{J}=47 \mathrm{~m} / \mathrm{s}, Z / D=6, d_{p}=220 \mu \mathrm{m}, \Gamma=0.18\right)$ 


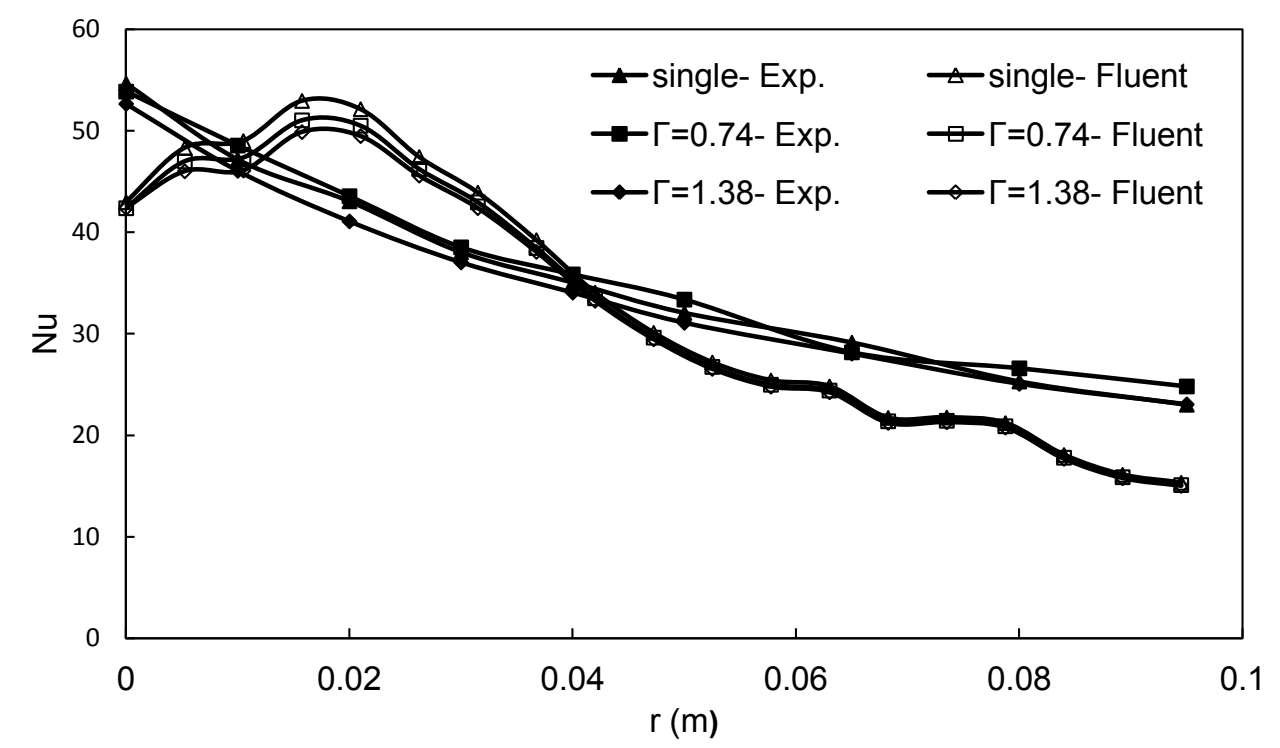

Figure 7a. Comparison of experimental Nusselt number with predictions for different loading ratios ( $\left.U_{J}=32.5 \mathrm{~m} / \mathrm{s}, Z / D=2, d_{p}=350 \mu \mathrm{m}\right)$

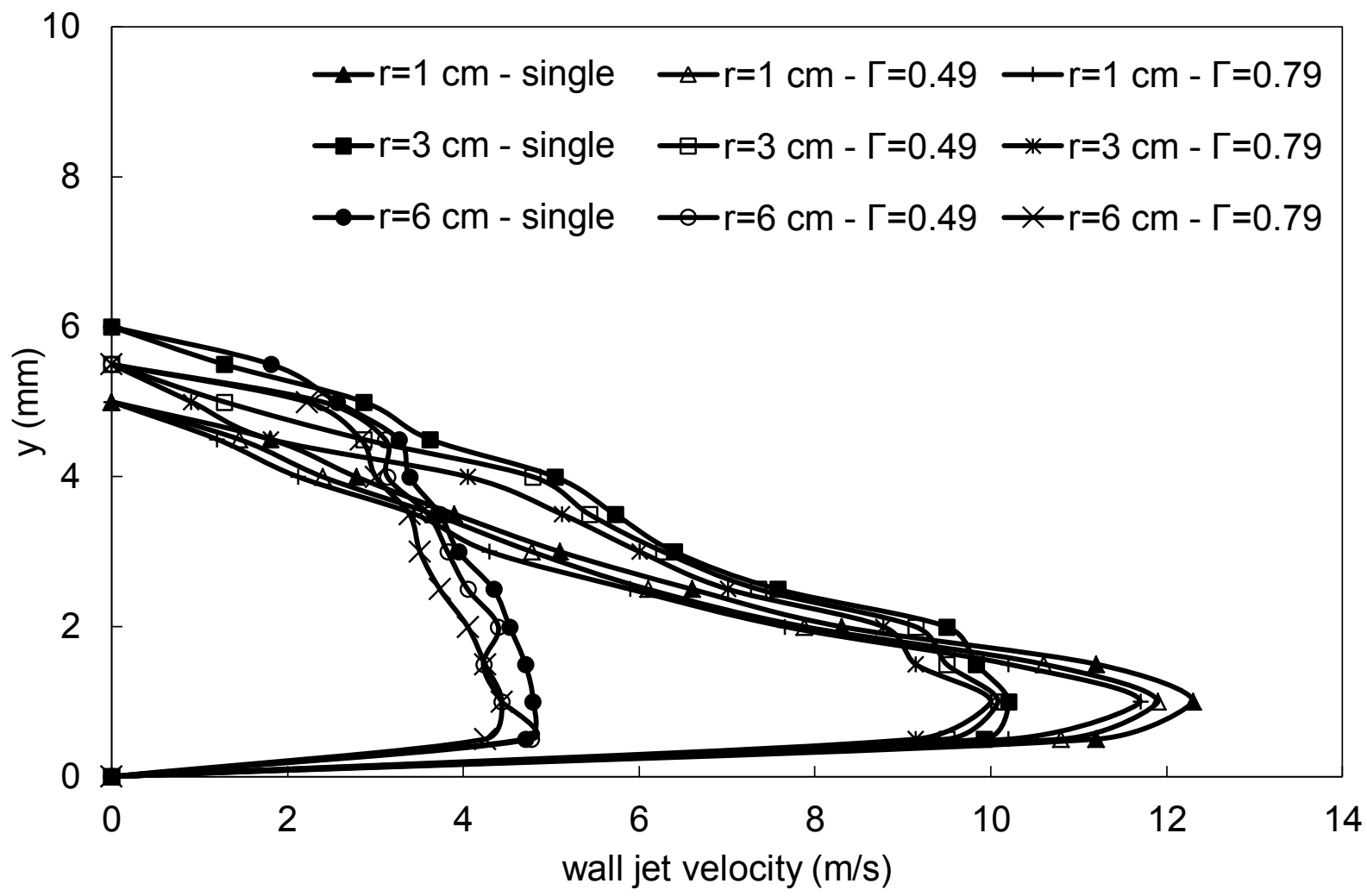

Figure $7 \mathrm{~b}$. Boundary layer development for single and two-phase flow $\left(\mathrm{U}_{\mathrm{J}}=47 \mathrm{~m} / \mathrm{s}, \mathrm{Z} / \mathrm{D}=2, \mathrm{~d}_{\mathrm{p}}=350 \mu \mathrm{m}\right)$ 


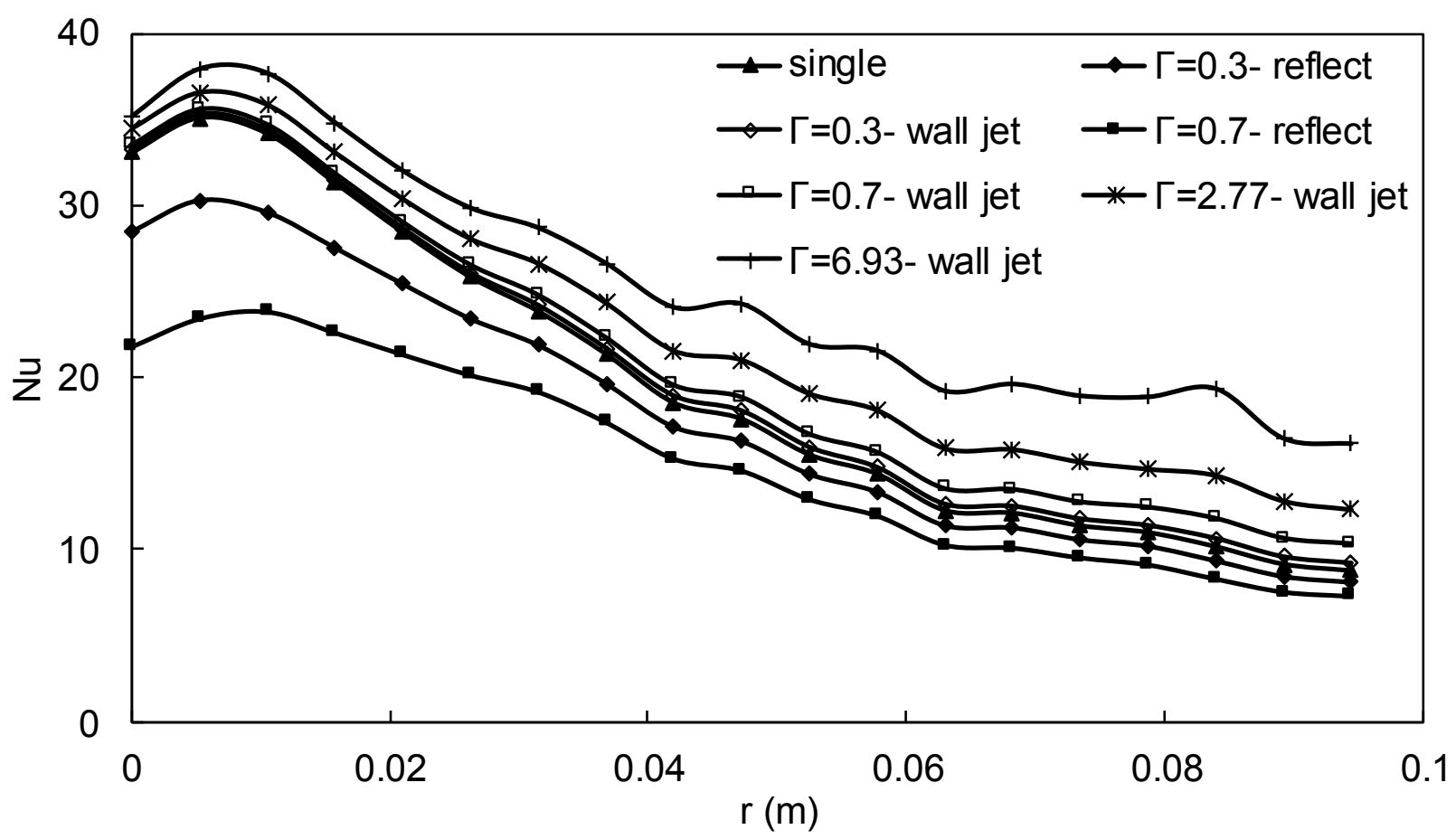

Fig 8a. Effect of particle behaviour (reflect and wall jet ) on local Nusselt number distribution from CFD simulation $\left(U_{\mathrm{J}}=15 \mathrm{~m} / \mathrm{s}, \mathrm{Z} / \mathrm{D}=6, \mathrm{~d}_{\mathrm{p}}=220 \mu \mathrm{m}\right)$

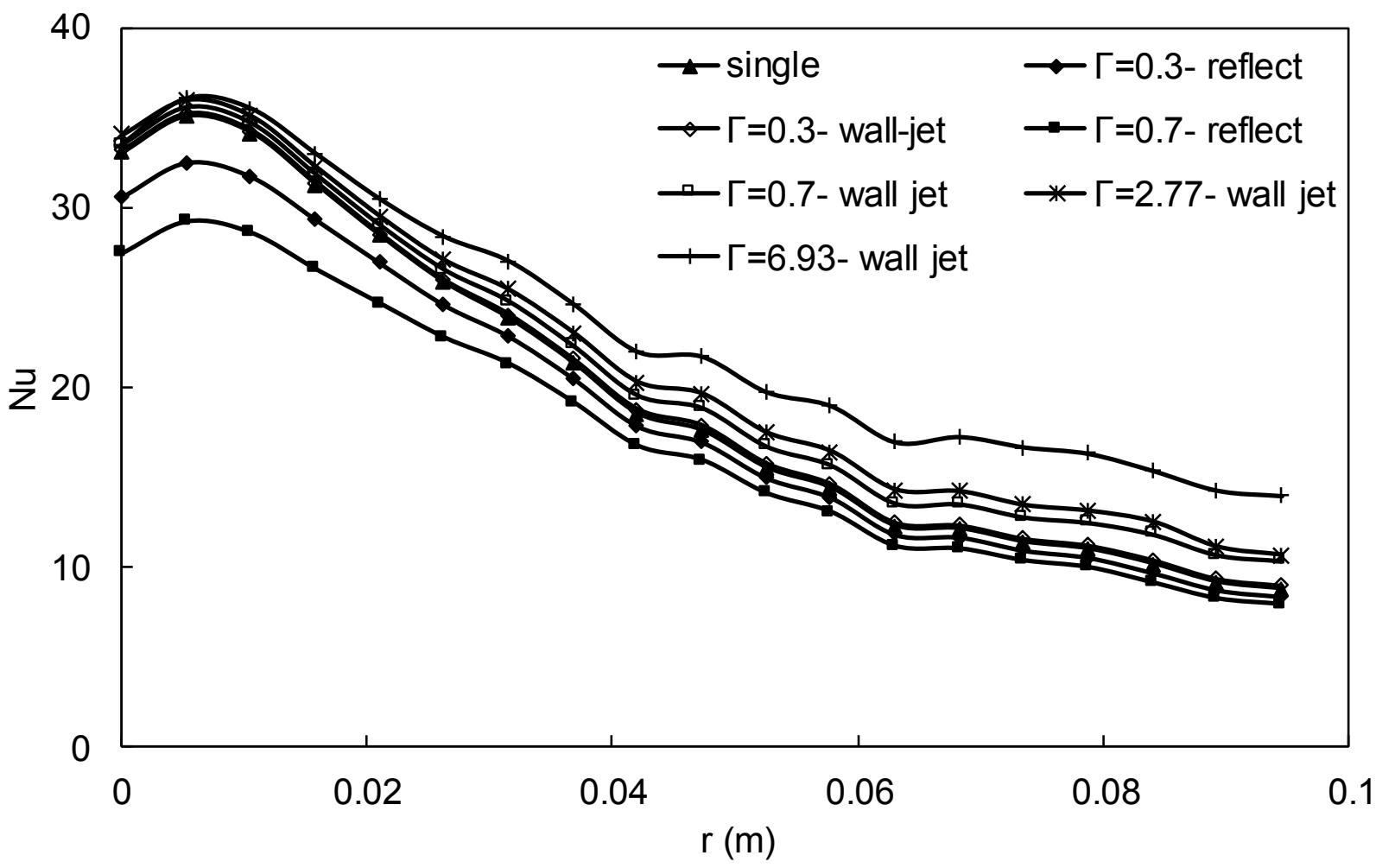

Fig 8b. Local Nusselt number distribution for loading ratios $\left(U_{\mathrm{J}}=15 \mathrm{~m} / \mathrm{s}\right.$, $\left.\mathrm{Z} / \mathrm{D}=6, \mathrm{~d}_{\mathrm{p}}=350 \mu \mathrm{m}\right)$ 


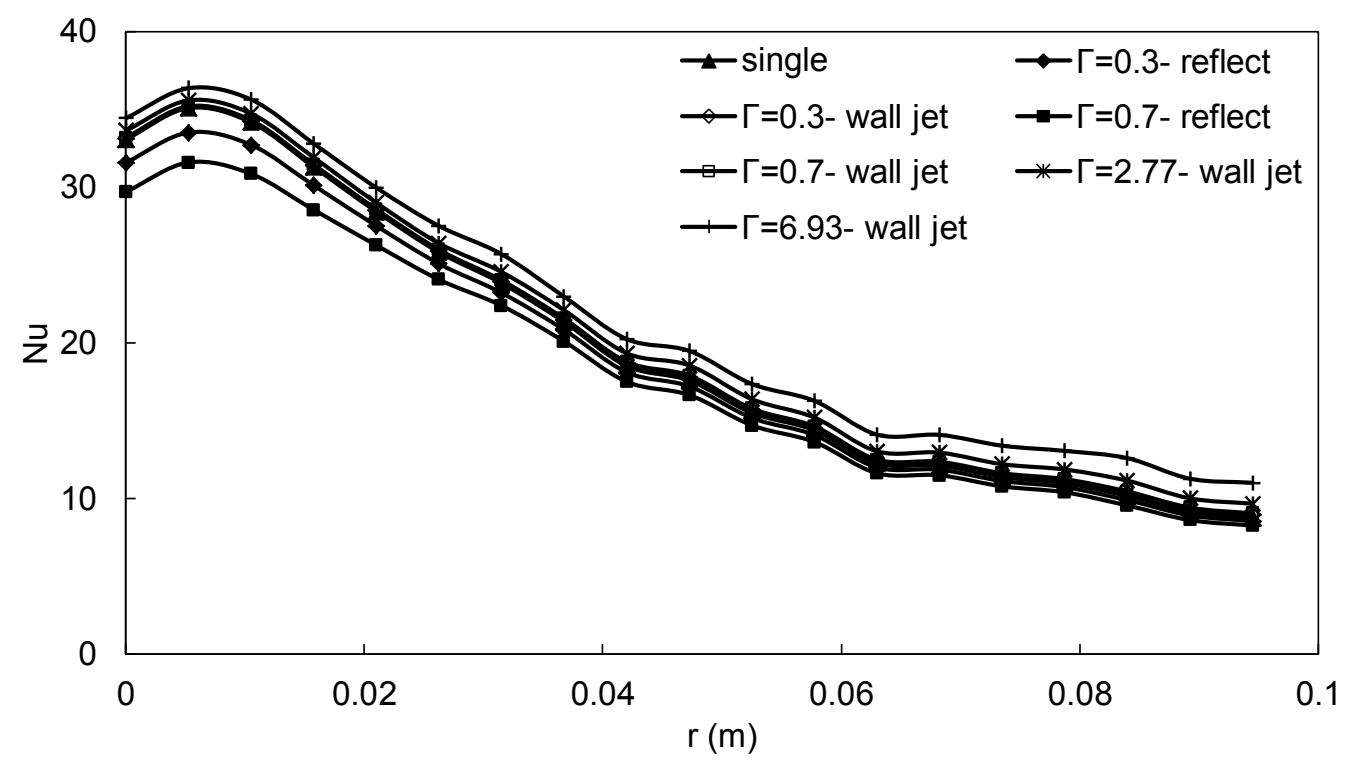

Fig 8c. Local Nusselt number distribution for loading ratios $\left(U_{J}=15 \mathrm{~m} / \mathrm{s}\right.$, $\left.\mathrm{Z} / \mathrm{D}=6, \mathrm{dp}_{\mathrm{p}}=550 \mu \mathrm{m}\right)$

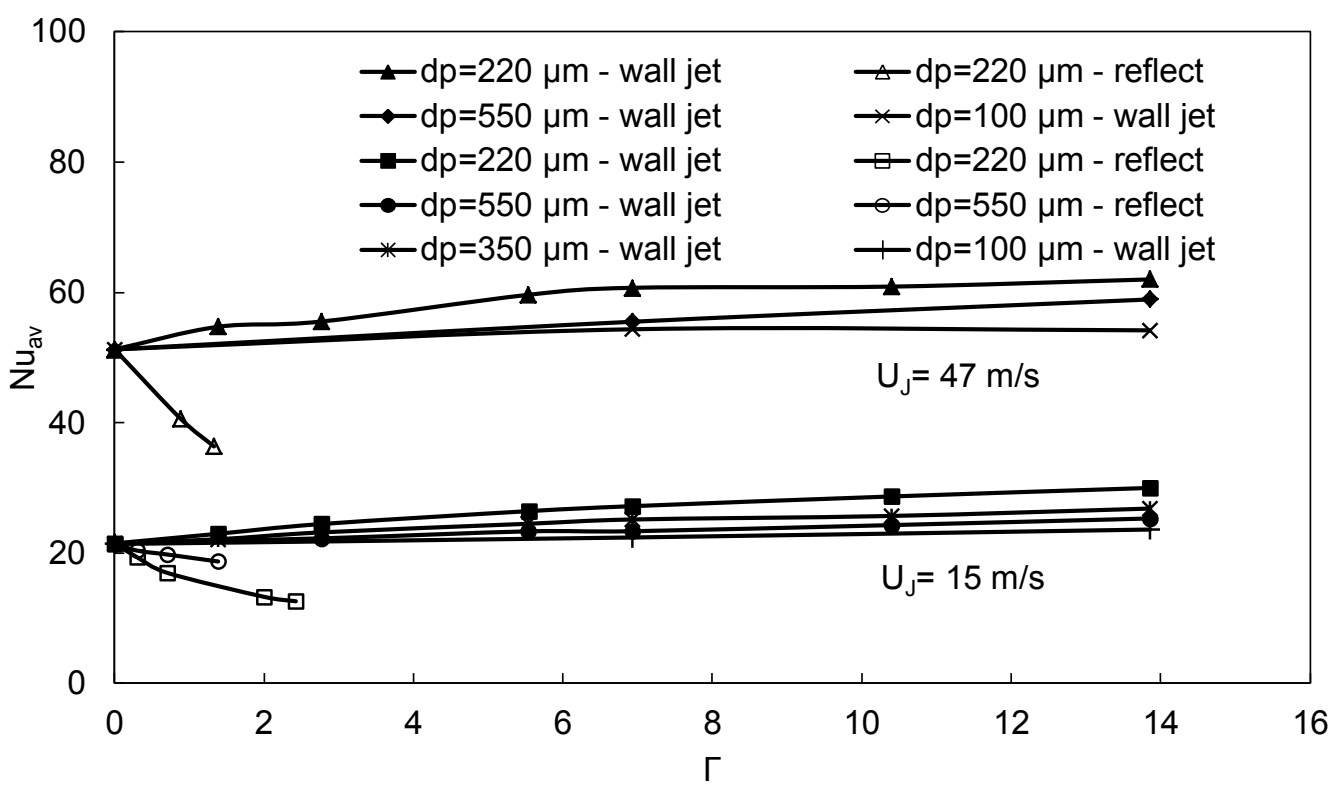

Fig 9. Variation of average Nu with loading ratio from CFD simulation $(Z / D=6)$ 